\title{
Research on the Misunderstanding and Trend of Chinese Population Economy Development under the Economic Transformation Background
}

\author{
Chongmei Li \\ School of Art and Law, Sichuan Agricultural Uniersity, \\ Ya'an,Sichuan, 625000 China
}

\begin{abstract}
In this paper, we conduct research on misunderstanding and trend of Chinese population economy development under the economic transformation background. New normal has become a new annotation, at present, China's economic development can be expected that with the continuous impact of the global financial crisis, the economic development momentum is not really appeared, downward pressure on economic development in a short period of time it difficult to get the effective relief. Know the new normal, therefore, to adapt to the new normal, leading the new normal will be the future a period of an important link to promote the development of our country's economy. Our research combines the general analysis of the economic transformation to form the better pattern for Chinese population economy development which is innovative.
\end{abstract}

Keywords- Population Economy, Economic Transformation, Background, Misunderstanding.

\section{Introduction}

China's decades of the progressive reform undoubtedly made remarkable achievements, but also accompanied by as we must face the consequences of that imbalance of the economic and social development and growing trend. The existence of the status quo and trend although it did not become barriers to economic growth and development, but looked from the long-term development, it will not only reflect the negative effect at the macro level, and it will affect China's future economic and social sustainable development. Imbalances if not mentioned the agenda and get the effective corrective, economic development will face anaemic or even stuck situation. Because the law of the social and the economic development show that when the development of the society into a well-off people of political equality, the balance of interests, and opportunities for development of the pursuit of fair and equal environment will be referred to a new level, we must not ignore this [1-2].

According to the literature review, the future of the Chinese economy can be summarized as the following aspects. (1) Economic growth will be mainly pulled by the urbanization, such as the mass consumer inner driving force. Our country's economy has already marched into the era of the mass consumption with the continuous development of national economy significantly higher per capita income level to meet the basic needs of life on the basis of private cars, household appliances and so on also began to rapid popularization residents consumption structure into a higher level of consumer demands will multi-level pulled the steady growth of the economic development. (2) Transform from the extensive to the integrated economic development. Change primary way of extensive growth to intensive attention should be paid to expand the connotation of production to optimize the industrial structure adjustment of economic structure especially pay attention to the development of the third industry because of the third industry dependence on resources and extent of damage to environment is relatively small to focus on the resource consumption to resource saving and environment friendly. (3) Strategic emerging industries, such as third industry will gradually rise. The third industry demand for resources and the environment as well as other economic industry high degree of damage to the environment is relatively low in 
place in the economic development in our country. According to the instructions of the state council of China will focus on basic development of energy conservation and environmental protection, a new generation of information technology, biology, high-end equipment manufacturing, new energy, new materials and new energy vehicles, and other emerging industries.

Economic transformation is a national and regional economic system, economic structure and the fundamental changes of economic system in a certain period of the time which is refers to the existing economic operation mode to the other a kind of new way of economic operation, the economic system update, is change the way of economic growth, economic structure that is a pillar industry and is the national economic system and structure of a process from quantitative change to qualitative change. China's economic transformation is the inherent requirement of system transformation as the guide to realize rapid development and is the only way to achieve sustainable development that is inevitable choice of world economic development trend. The figure one shows the current economy condition.

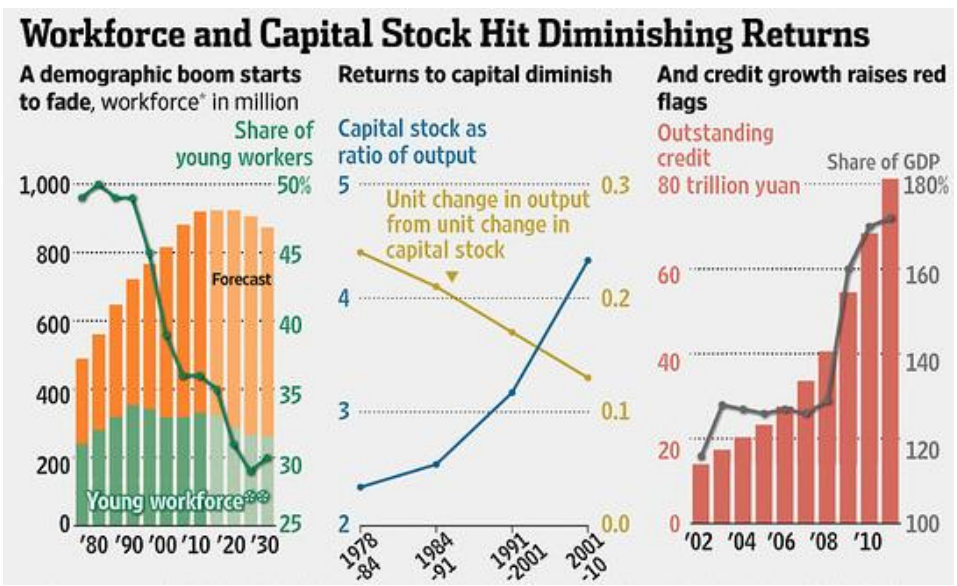

Figure 1. The General Condition of the Contemporary Chinese Economy

In this paper, we conduct research on misunderstanding and trend of Chinese population economy development under economic transformation background. The essence of sustainable development is within a certain time and space, under the condition of certain science and technology. To realize the harmonious development of the natural system and social system, its core is to realize the population, resource, economy and environment elements such as sustainable, balanced and orderly development. Within the field of the sustainable development, population, resource, economy, environment, and the interaction and mutual restriction of the science and technology constitute the dynamic open complex giant system. The sustainable development of population, economy, resources and environment is the integrated embodiment of sustainable development, society and the sustainable development of the population and economy is the premise of sustainable development as a whole. The coordination of the population, economic development, is refers to between the coordination and cooperation, mutual adaptation to maintain a reasonable proportion relationship development process. In the later sections, we will analyze the corresponding issues in detail [3].

\section{The Proposed Methodology}

The Current Condition of Chinese Economy. China's economy has entered a new growth cycle. But for the current China's economic growth accelerated belong to the normal cyclical 
upswing or the overheating, there are obvious. From the perspective of economic development strategy and to analyze and grasp the trend of China's economic development for the government to macroeconomic and microeconomic enterprises decisions has the very vital significance.

Theoretical reviews have proposed the listed challenges that Chinese economy should face with. (1) Ability rather than the external crisis. Most Chinese entrepreneurs in the business enterprise face of difficulties are its own competitive ability, and not just external market uncertainty. (2) Humanistic crisis rather than technical one. Without a good credit, there is no correct starting point, let alone increase good ability. (3) Structural crisis rather than cyclical crisis. Europe and Japan to the United States is not because the international situation is bad, but its domestic existing structural crisis. So that China should be alert to repeat such a crisis. (4) The government rather than market crisis. As the cell of society and the foundation, the enterprise for the role of social development is self-evident, therefore, entrepreneurs must be considered when making strategic economic background, but at the same time, moral and spiritual pursuit of an entrepreneur must possess [4-5].

In order to explore the direction of economic policy in China, we will analyze three core problems and can see from the traditional wisdom and modern knowledge learned what post-modern research method of combining. (1) Economic plan. Plan is a purely modern concept while it is based on the assumption, that to some extent we can manage the economy or society. Traditional society is based on the social habits and work, it is the past oriented, rather than future oriented. There is an implicit assumption that the society as an organism, there is no state intervention can also automatically heal its own disorder. Postmodernism view of planning includes both the natural balance of the traditional trust, also accept modern management tool. (2) Property rights. In the modern society, the property: directly by the individuals has someone. A certain group, company, or a government department as land use is determined by the individual decision making and public law, the traditional no longer binding but the most important feature of modern property right is the obligation of it with the group. The result is modern property system lead to social inequality. (3) Political authority or legitimacy. Related to the success of China's economic future of the third question is legitimate or the authority. Western economists have never put forward problems, their simple or take it for granted, or suppose it is by the people's general daily concerns and understandings.

The Economic Transformation. At present, the new normal economic development, has become China's economic hot words, not only because of the general secretary mentioned and expounded for many times, but it is essentially overall understanding of the economic situation at the present stage in China, is facing such situation at the national level to make the objective basis of response. To all over the world economy continues to weaken, the domestic economy and slow recovery of normal stayed, it needs us to strengthen the anticipation of the macro economic situation, and according to the actual objective decisively adjust strategic thinking with positive response to the economic properly the new changes of situation. The economic transformation of systemic risk and general risk distinguishing, the economic transformation of general risk only affect the performance of economic transformation, and systemic risk is due to the transition of the institutional reasons. This risk causes the failure of economic transformation or economic meltdown. Therefore, we need prevent transformation in the economic transformation of systemic risk and protect the national economic security [6]. 


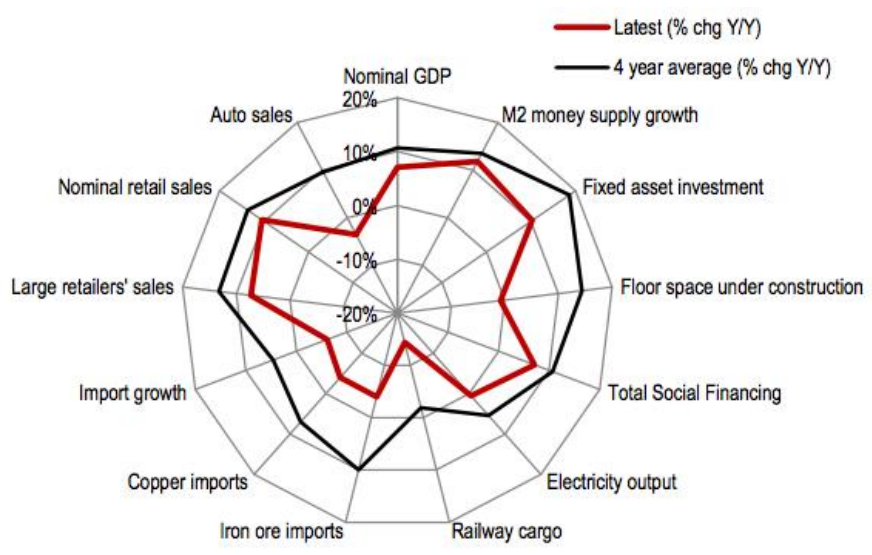

Figure 2. The Indivudual Characteristics of the Chinese Economy

Productivity is the decisive force of the social development. The development of productive forces will make society presents different state. Social transformation is one of the important performances in the period of social transition in contemporary China, its development is faced with a series of the problems and risks, including the ecological risk have become the current a bottleneck restricting the construction of China's modernization in order to ensure that the contemporary China's economic and social development with ecological risk management is necessary. Under the background, we should follow the listed suggestions for better transformation.

- Deepen the reform and build new advantages of system and mechanism. Reform is the biggest "bonus" of development we must stick to the top-level design combined with the innovation, with more courage, more forceful measures, fast to administrative examination and approval, with private investment in energy as high degree of marketization of resources configuration, regional open goal to move, and the power of the development of growing vitality.

- To plan as a whole, build new cities and economic advantages. Urbanization is the only way to modernization, it is the powerful engine to drive regional economic and social development, is also the general public to enjoy the important way of modern civilization. To new ideas, new goals, new measures to accelerate the integration of urban and rural development.

- To speed up the transformation, to build new industry competitive advantage. To speed up the economic transformation and upgrading is the only way to realize scientific development, but also a matter of the major decisions in the future. Must at the same time of steady growth, to correctly understand the tolerance of growth is slowing, firmly grasp the transformation of the mode of development of the main line unswervingly implement the development strategy.

- Wheeled, gaining new advantages of innovation and development. Adheres to strong driving force of innovation and the development, and fully give play to the role of the first productive force of science and technology and talents first resources, increase investment in science and technology innovation, optimization of technological innovation policy, focus on building an innovative city, fully arouse the whole society, especially the innovation of enterprise vitality.

The Population Economy Development. Human as the main body of economic activities, exists in certain region within the scope of and contact with the surrounding space, population development process in the history of space, as the population distribution. Population distribution involves both of terrain, climate, natural factors such as the natural resources, and productivity and production mode, economic development level and the way of economic activity, science and technology factors such as social and economic factors of the intimate relationship. Natural environment and social 
economic factors to the space distribution and evolution trend of population, and population distribution to a certain extent that reflects the differences in the levels of the regional natural environment and social economy. As a result, the population spatial distribution is reasonable or not has a profound impact on sustainable development of economic and social. Analysis of regional population spatial distribution, help to find out the population spatial distribution, to reveals the spatial evolution of the population distribution, and formulates reasonable regional economy and population policies promote resource, population, economic and the social sustainable development [7-8].

Through the above analysis, we can draw the following conclusion: the low level of urbanization is the result of the rapid growth of population in our country. And too large population size will restrict the urbanization process in China for a long time. The population growth rate of urbanization of our country the promoting function of limit function is greater than the rate of the economic growth: the excessive growth of population makes labor supply is greater than the demand for a long time, the status of the population is too large is the representation of urbanization and industrialization is an important factor in development of "divergence", so if our country should speed up the urbanization development must be strict control of general population growth. In this way can we urbanization development level consistent with the world.

\section{Conclusion}

In this paper, we conduct research on misunderstanding and trend of the Chinese population economy development under the economic transformation background. In charge with each kind of uncertainty environment, limited rational individuals through social interpersonal interaction to form close degree of various groups. In close and stable groups, individuals through trust relationship formed by the interaction of prompting them to consciously abide by the groups within the specifications; But in the information asymmetry in the society, the only rational legal system can coordinate the relationship between the different groups and their members. Norms and the relationship between the law and its status in the whole system constitutes a system structure of society, and to support these norms and the law of population structure, constitutes the social foundation of the institutional structure. Under this condition, we propose the optimal developmental approaches for the Chinese population economy with the analysis of economic transformation background. In the future, more corresponding research will be conducted for optimization.

\section{Acknowledgement}

This paper is financially supported by the project named: Research on the new rural construction and the rural human resources distribution change regulations.

\section{References}

[1] Ogden, Philip E. "Weaving demography into society economy and culture: progress and prospect in population geography." Progress in Human Geography 24.4 (2015): 627-40.

[2] Madduppa, Hawis H., et al. "Socio-economy of marine ornamental fishery and its impact on the population structure of the clown anemonefish Amphiprion ocellaris and its host anemones in Spermonde Archipelago, Indonesia." Ocean \& Coastal Management 100 (2014): 41-50.

[3] Almor, Tamar. "Conceptualizing paths of growth for technology-based born-global firms originating in a small-population advanced economy." International Studies of Management \& Organization 43.2 (2013): 56-78. 
[4] Agrawal, Ashish Kumar. "Role of Agro based Industries in the development of the Economy of District Jalaun." (2014).

[5] Hammer, Jeffrey S. "Ninth Annual Conference on Management of the Pakistan Economy Human Capital Development for Sustained Economic Growth/Governance and Service Delivery: Balancing Market and Government Failures." (2013).

[6] Vavreck, Lynn. "Want a Better Forecast? Measure the Campaign Not Just the
Economy." PS: Political Science \& Politics 47.02 (2014): 345-347.

[7] Niosi, Jorge. "Mario Cimoli, Giovanni Dosi and Joseph E. Stiglitz (eds): Industrial policy and development: The political economy of capabilities accumulation." Journal of Evolutionary Economics 22.2 (2012): 385-387.

[8] Caliendo, Lorenzo, et al. The impact of regional and sectoral productivity changes on the US economy. No. w20168. National Bureau of Economic Research, 2014. 